\title{
Simultaneous Determination of Amoxicillin and Diclofenac in Pharmaceutical Formulations Using UV Spectral Data and the PLS Chemometric Method
}

\author{
Miguel A. Cantarelli, $*$ Roberto G. Pellerano, ${ }^{*}$ Eduardo J. Marchevsky, $*$ and \\ Jose M. CAMIÑA**i \\ *Instituto de Química de San Luis (INQUISAL), Universidad Nacional de San Luis, Chacabuco y Pedernera \\ (5700) San Luis, Argentina \\ **Consejo Nacional de Investigaciones Científicas y Técnicas (CONICET), Av. Rivadavia 1917 (C1033AAJ) \\ Ciudad de Buenos Aires, Argentina
}

\begin{abstract}
A new method for the simultaneous determination of amoxicillin trihydrate (AMT) and sodium diclofenac (DIC) in pharmaceutical formulations is proposed. The resolution of binary mixtures of these drugs has been accomplished by using partial least squares (PLS) regression analysis. The model was obtained from UV spectral data and validated by internal cross-validation; it was used to find the concentration of analytes in some commercial samples. The method was applied in the concentration ranges of $0-120.0 \mathrm{mg} \mathrm{L}^{-1}$ for AMT and $0-16.0 \mathrm{mg} \mathrm{L}^{-1}$ for DIC, allowing a rapid, accurate and precise simultaneous estimation of the concentration of both analytes of interest in the presence of small amounts of different, unmodelled, absorbing excipients, in spite of their important spectral overlapping. The accuracy, precision and figures of merit (FOM) for AMT and DIC were calculated. This new method proved to be useful for a fast and simultaneous determination of AMT and DIC in pharmaceutical formulations.
\end{abstract}

(Received August 4, 2010; Accepted October 19, 2010; Published January 10, 2011)

\section{Introduction}

The development of suitable methods for the routine analysis of drugs in pharmaceutical preparations is currently of particular importance for the pharmaceutical and other industries as well as for government laboratories. ${ }^{1}$

Analytical quality is a key factor in the success of programmes for development, production and quality control of pharmaceuticals. In recent years, the regulations related to the quality control of medicines required by international pharmacopoeias have become strict, demanding modern pharmaceutical analysis as well as rapid, reliable and economic results. $^{2}$

Molecular absorption spectrometry is a frequent choice for pharmaceutical analyses. The strong spectral overlap of the bands exhibited by most active principles in the ultra violet (UV) region entails the use of separation methods whenever several of them are to be determined simultaneously.

Amoxicillin, $\{(2 S, 5 R, 6 R)-6-[(R)-2$-amino-2-( $p$-hydroxiphenyl)acetamid]-3,3-dimethyl-7-oxo-4-thia-1-azabicyclo[3.2.0]heptane2 -carboxilic acid trihydrate\}, is a $\beta$-lactam antibiotic used in humans and food-producing animals to treat several diseases. The presence of a benzyl ring in the side chain extends the antibacterial activity to gram-negative bacteria. ${ }^{3}$ The action mechanism of these antibiotics has not been unequivocally established, but it is thought they may interfere with

$\dagger$ To whom correspondence should be addressed.

E-mail: jcaminia@yahoo.com peptidoglycan bacterial cell wall synthesis in the organisms.

Diclofenac (DIC), sodium [o-(2,6-dichloroanilino)phenyl]acetate, derived from benzeneacetic acid, is a nonsteroidal antiinflammatory drug (NSAID) that is more usually found as a sodium or potassium salt with potent anti-inflammatory, analgesic, and antipyretic properties. It is widely used in the treatment of degenerative joint diseases and other arthritic conditions. ${ }^{4}$ Its mechanism of action is associated principally with the inhibition of prostaglandin synthesis (specifically, inhibition of cyclooxygenase). ${ }^{5,6}$

Different methods for the quantitative determination of these drugs in pharmaceutical preparations and biological fluids have been reported, including UV-vis spectroscopy, ${ }^{7-17}$ UV spectroscopy with chemometric analysis, ${ }^{18-20}$ spectrofluorometry, ${ }^{21-24}$ potentiometry, ${ }^{25-29}$ chromatography, ${ }^{30-37}$ electrophoresis capillary, ${ }^{38-42}$ Fourier transform spectroscopy, ${ }^{43}$ FT-Raman spectroscopy, ${ }^{44}$ FT-Raman spectroscopy with chemometric analysis, ${ }^{45}$ and sequential flow injection; ${ }^{46,47}$ however, none of the above procedures is suitable for the simultaneous determination of amoxicillin trihydrate (AMT) and DIC in commercial tablet pharmaceutical preparations. The instrumental methods above mentioned are important referential methods, but are based on expensive analytical instruments, which are not available for laboratories that carry out routine quality controls and have low economic resources.

On the other hand, the partial least square (PLS) regression method is a multivariate calibration tool that was used in a large number of previous works to determine the concentration of several analytes in a wide variety of samples, in combination with different spectroscopic techniques; ${ }^{48-52}$ PLS uses the 
original spectroscopic variables, thus allowing one to evaluate the concentration of mixtures of analytes..$^{53,54}$ The PLS-1 method is a multivariate calibration tool that uses a unique model for each analyte and predicts the concentration simultaneously in real samples. ${ }^{55}$

The quality of analytical results obtained in real samples of pharmaceutical formulations by the PLS-1 was validated externally by means of a test set. In order to evaluate the accuracy, researchers used the weighted least square (WLS) calibration method and the elliptical joint confidence region (EJCR) test. ${ }^{56,57}$ An external validation was used, comparing the results obtained with those provided by high performance liquid chromatography (HPLC) as a method of reference. ${ }^{58,59}$ The precision was evaluated by comparison of the standard deviation of the proposed and reference methods by means of an $F$-test.

\section{Experimental}

\section{Reagents and chemicals}

The water used in all studies was ultrapure water (18.2 $\mathrm{M} \Omega$ $\mathrm{cm}$ ) obtained from a Barnstead Easy-Pure RF compact ultrapure watersystem (Dubuque, IA). Amoxicillin trihydrate, sodium diclofenac, chloride acid, potassium hydroxide, potassium chloride, potassium dihydrogen phosphate, phosphoric acid and sodium dihydrogen phosphate were purchased from Sigma (St. Louis, MO). Methanol and acetonitrile HPLC grade were obtained from Merck (Durmsted, Germany).

\section{Instrumental}

UV spectral measurements were taken using an Ocean Optics Model CHEMUSB4 UV-vis spectrophotometer with a linear CCD array detector (Duiven, The Netherlands). The spectrophotometric measurements were carried out at room temperature (mean of about $20^{\circ} \mathrm{C}$ ) with an analysis time of less than $1 \mathrm{~h}$. The $\mathrm{pH}$ measurements were taken with a $\mathrm{pH}$ meter HORIBA F42 (Tokyo, Japan). The HPLC data were obtained by KONIK KNK-500-A Series (Miami, FL). A 25-cm C-18 column Lichrosorb RP18 (USA) was used with a KONIK UV detector (Miami, FL).

Millipore membrane type $\mathrm{HV}$ with a pore diameter of $0.45 \mu \mathrm{m}$ (Millipore, Bedford, MA) was used to filter the mobile phase and the samples, respectively.

The Unscrambler 6.11 by CAMO-ASA (Trondheim, Norway) software was used for the PLS-1 modeling and the figures of merit were calculated using the MVC1 software. ${ }^{60}$

\section{Standard solutions}

For the PLS method. AMT and DIC stock solutions were prepared by dissolving adequate quantities of both, AMT and DIC and completing to the mark with ultrapure water into a $1000-\mathrm{mL}$ volumetric flask to obtain a $1000 \mathrm{mg} \mathrm{L}^{-1}$ of standard solution. Intermediate stock solutions of 500 and $100 \mathrm{mg} \mathrm{L}^{-1}$ for AMT and DIC were prepared. All solutions were prepared one day before that of the analysis. The buffer solution of $\mathrm{pH} 1.0$ was prepared using chloride acid and potassium chloride, following $\mathrm{pH}$ values reported by Clarck and Lubs. ${ }^{61}$ The concentration matrix for the calibration step was obtained with a suitable amount of intermediate stock solution and transferred to a $25-\mathrm{mL}$ volumetric flask; $10 \mathrm{~mL}$ of chloride acid buffer solution $\mathrm{pH} 1.0$ were added and diluted to the mark with ultrapure water. The absorbance values of these mixtures were measured in $10 \mathrm{~mm}$ quartz cells between 200 and $300 \mathrm{~nm}$ at $0.2 \mathrm{~nm}$ intervals with respect to a blank of chloride acid buffer solution $\mathrm{pH} 1.0$.
For the HPLC method. a) AMT: the mobile phase was prepared with $96 \%(\mathrm{v} / \mathrm{v})$ potassium dihydrogen phosphate $0.05 \mathrm{~mol} \mathrm{~L}^{-1}$ and $4 \%(\mathrm{v} / \mathrm{v})$ acetonitrile. The standard solution was prepared by dissolving an accurately weighed quantity of AMT in a mobile phase to obtain a solution having a known concentration of $1.2 \mathrm{mg} \mathrm{mL}^{-1}$. b) DIC: the mobile phase was prepared with $70 \%(\mathrm{v} / \mathrm{v})$ methanol and 30\% (v/v) $\mathrm{pH} 2.5$ phosphate buffer. The standard solution was obtained by preparing a solution of DIC in methanol, which had a known concentration of $0.75 \mathrm{mg} \mathrm{mL}^{-1}$, and diluting an adequate volume of this stock solution with a mixture of methanol and water 70:30 (v/v) to obtain a solution having a known concentration of $1.5 \mu \mathrm{g} \mathrm{mL}^{-1}$.

\section{Real sample preparation}

Three different pharmaceutical formulations available in Argentina, containing AMT and DIC, were bought in local drugstores. They present the following compositions per tablet:

Formulation A: $500 \mathrm{mg}$ of amoxicillin trihydrate, $25 \mathrm{mg}$ of sodium diclofenac and excipients (celactose, magnesium stearate, lactose, titanium dioxide, hidroxypropilmethilcellulose, microcrystalline cellulose, polyethilenglycol and green dye FD\&C $\mathrm{N}^{\circ} 3$ ).

Formulation B: $500 \mathrm{mg}$ of amoxicillin trihydrate, $25 \mathrm{mg}$ of sodium diclofenac and excipients (magnesium stearate, titanium dioxide, microcrystalline cellulose, croscarmellose sodium, polyethilenglycol, Brilliant Blue Aluminum Lake).

Formulation C: $500 \mathrm{mg}$ of amoxicillin trihydrate, $50 \mathrm{mg}$ of sodium diclofenac and excipients (magnesium stearate, microcrystalline cellulose, croscarmellose sodium, Brilliant Blue Aluminum Lake).

Ten tablets were weighed individually to obtain representative average weights. The tablets were finely powdered and mixed. A mass corresponding to one tablet for each formulation was accurately weighed and dissolved in ultrapure water. Dissolution was carried out with the aid of an ultrasonic bath $(30 \mathrm{~min})$. These solutions were filtered through a $0.45-\mu \mathrm{m}$ membrane filter and diluted to the mark with ultrapure water in $1000-\mathrm{mL}$ volumetric flasks. These solutions were used the same day before the analysis.

For the PLS-1 procedure, an aliquot of $1 \mathrm{~mL}$ of each sample was added to $25-\mathrm{mL}$ volumetric flasks together with $10 \mathrm{~mL}$ of the respective buffer solution at the specified $\mathrm{pH}$, and ultrapure water was used to complete the volume. The spectra were obtained under the conditions already described.

For the HPLC procedure, DIC in formulations A and B was prepared by transferring $1 \mathrm{~mL}$ of sample solution to a $10-\mathrm{mL}$ volumetric flask and diluting it with $70 \%(\mathrm{v} / \mathrm{v})$ methanol and $30 \%$ (v/v) pH 2.5 phosphate buffer. For formulation C, DIC was prepared by transferring $1 \mathrm{~mL}$ of sample solution to a $25-\mathrm{mL}$ volumetric flask and diluting it with the same mobile phase. For AMT, $1 \mathrm{~mL}$ of sample solution was trasferred to a 250-mL volumetric flask and diluted to the mark with $96 \%(\mathrm{v} / \mathrm{v})$ potassium dihydrogen phosphate $0.05 \mathrm{~mol} \mathrm{~L}^{-1}$ and $4 \%(\mathrm{v} / \mathrm{v})$ acetonitrile.

\section{HPLC procedure}

HPLC conditions. a) For AMT: carrier flow $1.5 \mathrm{ml} \mathrm{min}{ }^{-1}$, absorbance measure using a single wavelength at $230 \mathrm{~nm}$. b) For DIC: carrier flow $1.0 \mathrm{~mL} \mathrm{~min}{ }^{-1}$, absorbance measure using a single wavelength at $254 \mathrm{~nm}$. The repeatability of the HPLC system was evaluated by performing successive injections $(n=6), 1.2 \mu \mathrm{g} \mathrm{mL}^{-1}$ for AMD and $1.5 \mu \mathrm{g} \mathrm{mL}^{-1}$ for DIC. The relative standard deviation (RSD) values were better than $1.2 \%$ for AMT and $3.4 \%$ for DIC. 
Table 1 Concentration matrix for the PLS-1 model

\begin{tabular}{crc}
\hline Standard & Amoxicillin $^{\mathrm{a}}$ & Diclofenac $^{\mathrm{a}}$ \\
\hline 1 & 0.00 & 0.00 \\
2 & 30.00 & 0.00 \\
3 & 60.00 & 0.00 \\
4 & 90.00 & 0.00 \\
5 & 120.00 & 0.00 \\
6 & 0.00 & 4.00 \\
7 & 30.00 & 4.00 \\
8 & 60.00 & 4.00 \\
9 & 90.00 & 4.00 \\
10 & 120.00 & 4.00 \\
11 & 0.00 & 8.00 \\
12 & 30.00 & 8.00 \\
13 & 60.00 & 8.00 \\
14 & 90.00 & 8.00 \\
15 & 120.00 & 8.00 \\
16 & 0.00 & 12.00 \\
17 & 30.00 & 12.00 \\
18 & 60.00 & 12.00 \\
19 & 90.00 & 12.00 \\
20 & 120.00 & 12.00 \\
21 & 0.00 & 16.00 \\
22 & 30.00 & 16.00 \\
23 & 60.00 & 16.00 \\
24 & 90.00 & 16.00 \\
25 & 120.00 & 16.00 \\
\hline
\end{tabular}

a. Concentration expressed in $\mathrm{mg} \mathrm{L}^{-1}$.

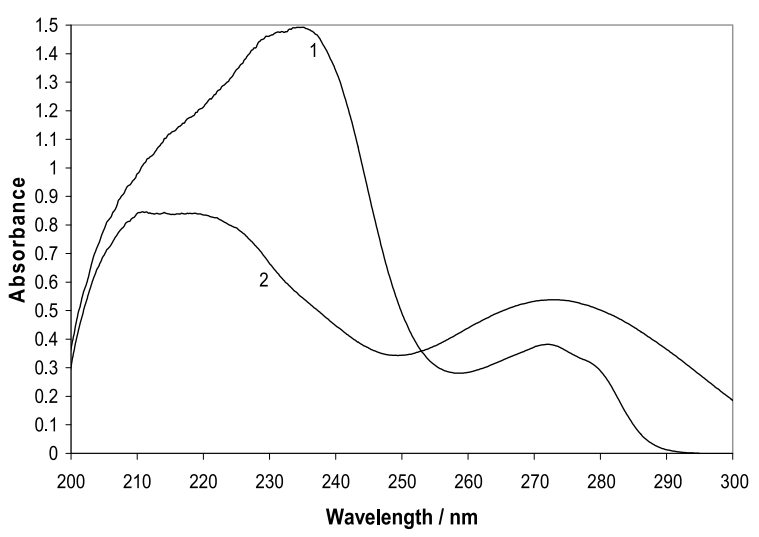

Fig. 1 UV spectra of: 1, amoxicillin $\left(120 \mathrm{mg} \mathrm{L}^{-1}\right) ; 2$, diclofenac (16 $\left.\mathrm{mg} \mathrm{L}^{-1}\right)$ in buffer solution $\mathrm{pH} 1$.

\section{Results and Discussion}

\section{The PLS model calibration set}

In order to make good predictions, multivariate calibration methods require a suitable experimental design of the standards in the calibration set. A full factorial $5^{2}$ design was used to build the calibration matrix, with five levels of concentration and two variables. The PLS- 1 models were obtained using a total of 25 standard solutions, which were obtained by adding adequate volumes of AMT and DIC intermediate stock solution. Table 1 shows the concentration matrix used in the calibration step. Figure 1 shows the spectral overlapping of AMT and DIC in a $200-300 \mathrm{~nm}$ range. The calibration step was performed by the a combination of the $\mathrm{A}$ absorbance matrix (or $\mathrm{R}$ response) and the $\mathrm{C}$ concentration matrix. ${ }^{53,62}$ The models were built using
Table 2 Percentage of explained variance, RMSEC and RMSEP for amoxicillin and diclofenac

\begin{tabular}{ccccccc}
\hline \multirow{2}{*}{ PC } & \multicolumn{2}{c}{ Amoxicillin } & & \multicolumn{2}{c}{ Diclofenac } \\
\cline { 2 - 3 } \cline { 5 - 6 } \cline { 5 - 6 } & Calibration & Validation & & Calibration & Validation \\
\hline 0 & 0 & 0 & & 0 & 0 \\
1 & 23.1 & 26.9 & & 79.8 & 76.0 \\
2 & 99.9 & 99.85 & & 99.9 & 99.9 \\
RMSEC & & 1.407 & & & 0.159 & \\
RMSEP & & 1.682 & & & 0.187 & \\
\hline
\end{tabular}

auto scaled data. The final models (for AMD and DIC) were obtained using internal validation (cross-validation method), where the model leaves out one standard of the calibration set every time. Then, the calibration and validation model errors were calculated through root mean squares of calibrations (RMSEC) and root mean squares of predictions (RMSEP). ${ }^{53,62}$

Each component (AMT and DIC) was independently modeled by the PLS-1, employing the optimum range of wavelength (for AMT from 258 - $292 \mathrm{~nm}$ and for DIC from 215 - $242 \mathrm{~nm}$ ) and the optimum number of PLS components (two PLS components were selected for AMT and DIC, respectively). The optimum number of PLS components was chosen for each analyte by selection of minimal values of RMSEC and RMSEP, which help to decide the adequate number of PLS components. Table 2 shows RMSEC, RMSEP and explained variance (cumulative percentage) of the PLS-1 models for AMT and DIC obtained in the calibration and validation processes. Table 2 shows a maximum for the percentage of variance explained values, using two PLS components for AMT and DIC in the calibration sets.

For the PLS-1 model, the observed-predicted concentrations plot for AMT was obtained, showing an $r^{2}$ correlation coefficient $=0.999$, abscissa and slope (mean \pm standard deviation): $0.63 \pm 1.10$ and $0.99 \pm 0.02$, respectively; the observed-predicted concentrations plot for DIC was also obtained, showing an $r^{2}$ correlation coefficient $=0.995$, abscissa and slope (mean \pm standard deviation): $1.75 \pm 2.01$ and $1.05 \pm$ 0.1 , respectively, which suggest a good fit in the models (ideal values of $r^{2}=1$, abscissa $=0$ and slope $=1$ ).

\section{PLS model test set}

The accuracy of each model for AMT and DIC was assessed using an independent validation set of sixteen samples: the amounts obtained in the determination of synthetic samples were compared with those actually added to the solutions. The validation test set was prepared with AMT and DIC concentrations different from those used for calibration, following a random design, but keeping all values between the corresponding calibration ranges for each analyte. This set was used to validate the PLS model. All samples were prepared and analyzed in triplicate in order to estimate the prediction errors of the PLS model.

For the accuracy test, the weighted least square (WLS) is the preferred technique to obtain the elliptical joint confidence region (EJCR). The linear model is based on the WLS method, which takes into account that the comparable errors in both axes should fit a straight line where the intercept is not significantly different from 0 and the slope not significantly different from $1 .{ }^{56}$ The WLS method was used with the test set in the proposed method. The results include the theoretically expected value $(1,0)$, indicating that the proposed methodology is accurate and free of systematic error. 


\section{Figures of merit (FOM)}

The determination of figures of merit (FOM) is an important requisite for the validation of these kinds of multivariate methods, aiming at their possible acceptance by the regulatory agencies in the future.

The FOM of this method were calculated and used to compare analytical methods: limit of detection (LOD), limit of quantification (LOQ), sensibility $\left(\mathrm{SEN}_{\mathrm{k}}\right)$, selectivity $\left(\mathrm{SEL}_{\mathrm{k}}\right)$ and analytical sensibility $\left(\gamma_{\mathrm{k}}\right)$. $\operatorname{SEN}_{\mathrm{k}}$ are described as:

$$
\operatorname{SEN}_{\mathrm{k}}=\frac{1}{\left\|\mathbf{b}_{\mathrm{k}}\right\|}
$$

Where $\mathbf{b}_{\mathrm{k}}$ is the vector of the regression coefficient for the $\mathrm{k}$ analytes. LOD is defined as:

$$
\mathrm{LOD}=3.3\left\|\boldsymbol{\delta}_{\mathrm{r}}\right\|\left\|\mathbf{b}_{\mathrm{k}}\right\|
$$

Where $\left\|\delta_{\mathrm{r}}\right\|$ is a measure of instrumental noise. LOQ is defined as:

$$
\mathrm{LOQ}=3 \mathrm{LOD}
$$

$\mathrm{SEL}_{\mathrm{k}}$ is defined as:

$$
\text { SEL }_{\mathrm{k}}=\frac{\left\|\mathbf{s}_{\mathrm{k}}{ }^{*}\right\|}{\left\|\mathbf{s}_{\mathrm{k}}\right\|}
$$

Here $\mathbf{s}_{\mathrm{k}}$ is the vector of spectral sensitivities of $\mathrm{k}$ components in the pure form, while $\mathbf{S}_{\mathrm{k}}{ }^{*}$ is the projection onto the net analyte signal space. ${ }^{63,64}$

The $\left\|\delta_{\mathrm{r}}\right\|$ values are available from calibration measurements and instrumental blank replication. In this work, the $\left\|\delta_{\mathrm{r}}\right\|$ value was estimated from the standard deviation of blanks ${ }^{65}$ (which included solvent-water- and buffer solution). $\mathbf{s}_{\mathrm{k}}$ is the spectrum vector of the $k$ th component in the calibration matrix. $\left\|\mathbf{s}_{\mathrm{k}}\right\|$ is calculated by the $\mathrm{MVC1}^{60}$ software based on the net analyte signal (NAS). In PLS inverse calibration, the total analyte signal of the $k$ th component is replaced by the length of the mixture spectrum, ${ }^{66}$ using a concentration of analyte $=1$. This

Table 3 Figures of merit (FOM) calculated for the PLS-1 method

\begin{tabular}{lcl}
\hline \multicolumn{1}{c}{ Figures of merit } & Amoxicillin & Diclofenac \\
\hline Limit of detection (LOD) $/ \mathrm{mg} \mathrm{mL}^{-1}$ & 4.90 & 1.10 \\
Limit of quantification (LOQ)/mg mL & 16.20 & 3.63 \\
Sensibility (SEN) & $4.4 \times 10^{-3}$ & 5.6 \\
Selectivity (SEL) & 0.034 & 0.066 \\
Analytical sensibility $(\gamma) / \mathrm{L} \mathrm{mg}^{-1}$ & 4.4 & 5.6 \\
\hline
\end{tabular}

approach is frequently used to calculate the pure spectra of each analyte in a mixture. ${ }^{63,64,67}$

Finally, analytical sensibility is defined as:

$$
\gamma_{\mathrm{k}}=\frac{\mathrm{SEN}_{\mathrm{k}}}{\left\|\delta_{\mathrm{r}}\right\|}
$$

Table 3 shows the figures of merit for AMT and DIC, including the limit of detection (LOD), sensibility (SEN), analytical sensibility $\left(\gamma_{\mathrm{k}}\right)$, and selectivity (SEL).

\section{Real samples prediction and HPLC validation results}

Three real samples of the above mentioned pharmaceutical formulations were analyzed with five replicates by applying the PLS-1 model. Results were validated by the HPLC method. The results obtained by the PLS-1 and HPLC methods are shown in Table 4.

The precisions of the PLS-1 and HPLC reference methods were statistically compared. ${ }^{68}$ The $F$ test was used for every sample to compare variances, obtaining $F$ values from 2.5 to 5.5 for AMT and values from 2.2 to 3.0 for DIC, which do not exceed the theoretical value of $95 \%$ confidence level $\left(F_{\text {crit }}=\right.$ 9.605). Such result indicate that both methods do not differ statistically in their precision. The accuracy between both methods, PLS-1 and HPLC, was evaluated using the percentage relative error, which was less than $7 \%$ in all cases.

\section{Recovery test in real samples}

The method of standard addition is considered as a validation method. ${ }^{69,70}$ In order to demonstrate the validity of our method, a recovery study was carried out. This evaluation is important to know the behavior of the model in relation to unknown samples, without external validation.

Table 5 shows the results of added-found concentrations in both analytes in real samples studied in this work. Appropriate quantities of stock solutions of AMT and DIC were added to diluted real samples (dilution 1:5) taking into account the concentrations obtained in Table 4. In all cases, the recoveries of the PLS model in real samples has a range from 98.0 to $103.0 \%$ and 97.0 to $103.3 \%$ for AMT and DIC, respectively, which indicates that, due to dilution, the matrix effects do not alter the predictive ability of the model, showing good recovery degree in all samples.

\section{Conclusions}

The application of multivariate calibration techniques has resulted in improved applicability, precision and accuracy in

\begin{tabular}{|c|c|c|c|c|c|c|c|c|}
\hline \multirow{2}{*}{ Form } & \multirow{2}{*}{$\begin{array}{c}\text { Label } \\
\text { value }^{\mathrm{a}, \mathrm{b}}\end{array}$} & \multicolumn{3}{|c|}{ Amoxicilin } & \multirow{2}{*}{$\begin{array}{c}\text { Label } \\
\text { value }^{\mathrm{a}, \mathrm{b}}\end{array}$} & \multicolumn{3}{|c|}{ Diclofenac } \\
\hline & & PLS-1 ${ }^{\mathrm{c}}$ & HPLC $^{c}$ & $\mathrm{ER}, \%^{\mathrm{d}}$ & & PLS- $1^{\mathrm{c}}$ & HPLC $^{c}$ & $\mathrm{ER}, \%^{\mathrm{d}}$ \\
\hline $\mathrm{A}$ & 500.0 & $507.0 \pm 12.0$ & $498.0 \pm 7.0$ & 1.8 & 25.0 & $23.8 \pm 1.2$ & $25.5 \pm 0.7$ & -6.8 \\
\hline B & 500.0 & $491.0 \pm 14.0$ & $509.0 \pm 6.0$ & -3.6 & 25.0 & $23.4 \pm 1.5$ & $24.4 \pm 1.0$ & -4.0 \\
\hline $\mathrm{C}$ & 500.0 & $489.0 \pm 10.0$ & $504.0 \pm 6.0$ & -3.0 & 50.0 & $53.2 \pm 1.4$ & $51.5 \pm 0.8$ & 3.4 \\
\hline
\end{tabular}
multicomponent spectral analysis, even in those cases in which there is considerable overlapping of spectral features. The results obtained show that direct spectrophotometric analysis

Table 4 Validation of real samples of PLS-1 model in comparison with HPLC

a. Concentrations expressed in $\mathrm{mg} /$ tablet. b. Tablet label declared. c. Average \pm standard deviation of five determinations per sample.

d. Relative error expressed in percentage. 
Table 5 Added-found concentrations in real sample set to evaluate recovery degree

\begin{tabular}{|c|c|c|c|c|}
\hline & $\begin{array}{c}\text { Base } \\
\text { value } \\
\text { mg L }^{-1}\end{array}$ & $\begin{array}{l}\text { Quantity } \\
\text { added/ } \\
\mathrm{mg} \mathrm{L}^{-1}\end{array}$ & $\begin{array}{l}\text { Quantity } \\
\text { found }{ }^{\mathrm{a}} \\
\mathrm{mg} \mathrm{L}^{-1}\end{array}$ & $\begin{array}{c}\text { Recovery, } \\
\%^{\mathrm{b}}\end{array}$ \\
\hline \multicolumn{5}{|c|}{ Formulation A } \\
\hline AMT & 101.40 & 10.00 & 111.70 & 103.0 \\
\hline DIC & 4.76 & 2.00 & 6.70 & 97.0 \\
\hline \multicolumn{5}{|c|}{ Formulation B } \\
\hline AMT & 98.20 & 10.00 & 108.30 & 101.0 \\
\hline DIC & 4.68 & 2.00 & 6.71 & 101.5 \\
\hline \multicolumn{5}{|c|}{ Formulation $\mathrm{C}$} \\
\hline AMT & 97.80 & 10.00 & 107.60 & 98.0 \\
\hline DIC & 10.64 & 4.00 & 14.77 & 103.3 \\
\hline
\end{tabular}

a. Mean value $(n=5)$.

b. [(found - base)/added $] \times 100$.

with a multivariate calibration technique can be an alternative and fast method for the simultaneous determination of these drugs in pharmaceutical real samples. The method is simple, fast, accurate, and highly suitable for routine quality-control determinations, and useful for the analysis of drug content in combined tablet formulations.

\section{Acknowledgements}

We would like to thank Prof. Roberto Olsina (Universidad Nacional de San Luis) for providing the Unscrambler 6.11 software. We are also grateful for grants received from Universidad Nacional de La Pampa, Universidad Nacional de San Luis and Consejo Nacional de Investigaciones Científicas y Técnicas (CONICET) that provided financial support for this research

\section{References}

1. M. S. Boeris, J. M. Luco, and R. A. Olsina, J. Pharm Biomed. Anal., 2000, 24, 259.

2. A. M. Pimenta, M. C. B. S. M. Montenegro, A. N. Aráujo, and J. Martínez Calatayud, J. Pharm. Biomed. Anal., 2006, $40,16$.

3. H. H. Handsfield, H. Clark, J. F. Wallace, K. K. Holmes, and M. Turck, Chemotherapy, 1973, 3, 262.

4. S. C. Sweetman, "The Complete Drug Reference", 35th ed., 2006, Pharmaceutical Press, London, Chicago.

5. J. A. Mitchell and T. D. Warner, J. Pharmacol., 1999, 128, 1121.

6. C. M. Adeyeye and P. K. Li, "Analytical Profiles of Drug Substances", 1990, Academic Press, New York.

7. R. L. De Souza and M. Tubino, J. Braz. Chem. Soc., 2005, 16, 1068.

8. A. A Matin, M. A. Farajzadeh, and A. Joyuban, Il Farmaco, 2005, 855 .

9. H. Fabre, S. W. Sun, B. Mandrou, and H. Maillols, Analyst, 1993, 118,1061

10. J. C. Botello and G. Pérez Caballero, Talanta, 1995, 42, 105.

11. M. S. Garcia, M. I. Albero, C. Sánches-Pedreño, and J. Molina, J. Pharm. Biomed. Anal., 1998, 17, 267.

12. Y. C. de Micalizzi, N. B. Pappano, and N. B. Debattista, Talanta, 1998, 47, 525 .
13. M. L. Fernández de Córdova, P. Ortega Barrales, and A. Molina Díaz, Anal. Chim. Acta, 1998, 369, 263.

14. G. A. Saleh, Analyst, 1996, 121, 641.

15. B. S. Nagaralli, J. Seetharamappa, and M. B. Melwanki, J. Pharm. Biomed. Anal., 2002, 29, 859.

16. H. Salem and G. A. Saleh, J. Pharm. Biomed. Anal., 2002, $28,1205$.

17. H. Salem, Anal. Chim. Acta, 2004, 515, 333.

18. M. M. Sena, Z. F. Chaudhry, C. H. Collins, and R. J. Poppi, J. Pharm. Biomed. Anal., 2004, 743.

19. P. M. Castellano, S. E. Vignaduzzo, R. M. Maggio, and T. S. Kaufman, Anal. Bioanal. Chem., 2005, 382, 1711.

20. J. Ghasemi, A. Niazi, and S. Ghobadi, J. Chin. Chem. Soc., 2005, 52, 1049.

21. A. García-Reiriz, P. C. Damiani, and A. C. Olivieri, Anal. Chim. Acta, 2007, 588, 192.

22. L. A. Carreira, M. Rizk, Y. El-Shabrawy, N. A. Zakhari, and S. S. Toubar, J. Pharm. Biomed. Anal., 1995, 13, 1331.

23. P. C. Damiani, M. Bearzotti, M. A. Cabezón, and A. C. Olivieri, J. Pharm. Biomed. Anal., 1999, 20, 587.

24. J. A. Arancibia, M. A. Boldrini, and G. M. Escandar, Talanta, 2000, 52, 261.

25. A. O. Santini, H. R. Pezza, and L. Pezza, Talanta, 2006, 68 , 636.

26. A. M. Pimenta, A. N. Araújo, and M. C. B. S. M. Montenegro, Anal. Chim. Acta, 2002, 470, 185.

27. M. Shamsipur, F. Jalali, and S. Ershad, J. Pharm. Biomed. Anal., 2005, 37, 943.

28. S. S. M. Hassan, W. H. Mahmoud, M. A. F. Elmosallamy, and M. H. Almarzooqui, J. Pharm. Biomed. Anal., 2005, 37,315 .

29. P. Daneshgar, P. Norouzi, M. R. Ganjali, R. Dinarvand, and A. A. Moosavi-Movahedi, Sensors, 2009, 9, 7903.

30. S. T. Patil, M. Sundaresan, I. C. Bhoir, and A. M. Bhagwat, Talanta, 1998, 47, 3 .

31. L. González, G. Yuln, and M. G. Volonté, J. Pharm. Biomed. Anal., 1999, 20, 487.

32. M. E. Abdel-Hamid, L. Novotny, and H. Hamza, J. Pharm. Biomed. Anal., 2001, 24, 587.

33. B. X. Mayer, K. Namiranian, P. Dehghanyar, R. Stroh, H. Mascher, and M. Müller, J. Pharm. Biomed. Anal., 2003, 33,745 .

34. A. Chmielewska, L. Konieczna, A. Plenis, and $\mathrm{H}$ Lamparczyk, J. Chromatogr., B, 2006, 839, 102.

35. C. Nebot, S. W. Gibb, and K. G. Boyd, Anal. Chim. Acta, 2007, 598, 87.

36. A. Panusa, G. Multari, G. Incarnato, and L. Gagliardi, $J$. Pharm. Biomed. Anal., 2007, 43, 1221.

37. M. Dousa and R. Hosmanová, J. Pharm. Biomed. Anal., 2005, 37, 373.

38. E. G. De-Jong, J. Kiffers, and R. A. A. Maes, J. Pharm. Biomed. Anal., 1989, 7, 1617.

39. M. I. Bailón Pérez, L. Cuadros Rodríguez, and C. Cruces-Blanco, J. Pharm. Biomed. Anal., 2007, 43, 746.

40. Y. M. Li, A. Van Schepdael, Y. Zhu, E. Roets, and J. Hoogmartens, J. Chromatogr., A, 1998, 812, 227.

41. J. H. Cutting, J. A. Hurlbut, and J. N. Sofos, J. AOAC Int., 1997, 80, 951 .

42. C. García-Ruiz and M. L. Marina, Electrophoresis, 2006 , 27, 266

43. G. Parisotto, M. F. Ferrão, J. C. Furtado, and R. F. Molz Rev. Bras. Cienc. Farm., 2007, 43, 89.

44. S. Mazurek and R. Szostak, J. Pharm. Biomed. Anal., 2006, 40,1235

45. S. Mazurek and R. Szostak, J. Pharm. Biomed. Anal., 2008, 
48,814

46. T. Pérez-Ruiz, C. Martínez-Lozano, A. Sanz, and M. T. San Miguel, J. Pharm. Biomed. Anal., 1997, 16, 249.

47. M. Q. Al-Abachi, H. Haddi, and A. M. Al-Abachi, Anal. Chim. Acta, 2005, 554, 184.

48. R. G. Brereton, Analyst, 2000, 125, 2125.

49. M. Forina, M. C. Casolino, and C. de la Pezuela Martinez, J. Pharm. Biomed. Anal., 1998, 18, 21.

50. V. A. Lozano, J. M. Camiña, M. S. Boeris, and E. J. Marchevsky, Talanta, 2007, 73, 282.

51. M. J. Culzoni, M. M. De Zan, J. C. Robles, V. E. Mantovani, and H. C. Goycochea, J. Pharm. Biomed. Anal., 2005, 39, 1068.

52. M. A. Cantarelli, R. G. Pellerano, E. J. Marchevsky, and J. M. Camiña, Food Chem., 2009, 115, 1128.

53. K. R. Beebe, R. J. Pell, and M. B. Seasholtz, "Chemometrics: A Practical Guide", 1998, John Wiley and Sons, New York.

54. D. L. Massart, B. G. M. Vandeginste, L. M. C. Buydens, S. De Jong, P. J. Lewi, and J. Smeyers-Verbeke, "Handbook of Chemometrics and Qualimetrics", 1997, Elsevier, Amsterdam.

55. H. Martens and T. Naes, "Multivariate Calibration", 1996, John Wiley and Sons, New York.

56. A. G. González, M. A. Herrador, and A. G. Asuero, Talanta, 1999, 48, 729.

57. J. A. Arancibia, A. Rullo, A. C. Olivieri, S. Di Nezio, M. Pistonesi, A. Lista, and B. S. Fernández Band, Anal. Chim. Acta, 2004, 512, 157.

58. U. S. Pharmacopeia 30 National Formulary 25, 2007, The
United States Pharmacopeia Convention Inc., Rockville, 1922.

59. U. S. Pharmacopeia 30 National Formulary 25, 2007, The United States Pharmacopeia Convention Inc., Rockville, 1402.

60. A. C. Olivieri, H. C. Goicoechea, and F. A. Inón, MVC1: Intell. Lab. Syst., 2004, 73, 189.

61. L. Meites, "Handbook of Analytical Chemistry", 1963, McGraw Hill, New York.

62. K. Esbensen, S. Schönkopf, and T. Midtgaard, "Multivariate Analysis in Practice", 1996, CAMO, Trondheim.

63. N. M. Faber and B. R. Kowalski, J. Chemom., 1997, 11, 181.

64. A. Lorber, K. Faber, and B. R. Kowalsky, Anal. Chem., 1997, 69, 1620.

65. R. Bro and C. M. Andersen, J. Chemom., 2003, 17, 646.

66. A. C. Olivieri, N. M. Faber, J. Ferré, R. Boqué, J. H. Kalivas, and H. Mark, Pure Appl. Chem., 2006, 78, 633.

67. M. Ostra, C. Ubide, M. Vidal, and J. Zuriarrain, Analyst, 2008, 133, 532.

68. J. N. Miller and J. C. Miller, "Estadística y Quimiometría para Química Analítica”, 2002, Pearson Educación S. A., Madrid.

69. ICH Harmonised Tripartite Guideline, 1994, Text on Validation of Analytical Procedures.

70. E. Prichard, G. M. Mackay, and J. Points, "Trace Analysis: A Structures Approach to Obtaining Reliable Results", 1999, The Royal Society of Chemistry, Loindon, 38. 